Anales de Geografía de la Universidad Complutense ISSN: 0211-9803

http://dx.doi.org/10.5209/AGUC.66940

\title{
El plano catastral de Carlos Colubi: propuesta metodológica para la reconstitución gráfica del terrazgo madrileño en el siglo XIX
}

\author{
Luis De Sobrón Martínez ${ }^{1}$ \\ Recibido: 6 de junio del 2018 / Enviado a evaluar: 7 de febrero del 2019 / Aceptado: 17 de octubre del 2019
}

\begin{abstract}
Resumen. Se propone un método de reconstitución, sobre una base cartográfica actual, del Plano catastral del término de Madrid trazado por Carlos Colubi, considerándolo como imagen del territorio madrileño en el momento clave previo al proceso proyectual del ensanche de la ciudad. Se plantean cuatro fases de trabajo, adaptando algunos planteamientos ya ensayados en otras investigaciones y proponiendo otros nuevos a partir de las fuentes documentales específicas del territorio y el momento histórico estudiado, fundamentalmente los planos de replanteo y alineaciones de los expedientes de construcción del Archivo de Villa. El método intenta ser un instrumento gráfico de análisis que permita profundizar en el conocimiento de la transición de la estructura parcelaria y viaria rural a la forma urbana actual del ensanche decimonónico. Además, las averiguaciones realizadas han arrojado nuevos datos sobre el origen y datación del plano de Colubi, documento cartográfico de primer orden en la historia del urbanismo madrileño.
\end{abstract}

Palabras clave: plano catastral; Carlos Colubi; forma urbana; ensanche; metodología; reconstitución gráfica.

\section{[en] The cadastral plan by Carlos Colubi: methodological proposal for the graphic reconstitution of Madrid's surroundings in the 19th century}

\begin{abstract}
It is proposed a graphic reconstitution method, on a current cartographic basis, of the Madrid cadastral plan drawn by Carlos Colubi. This plan is a representation of Madrid's surroundings at the key moment prior to the design process of the city expansion. Four phases are proposed, adapting some approaches already tested in previous researches and proposing new ones based on the specific documentary sources of the territory and the historical moment studied, basically the surveying and arrangement drawings of the construction files of the Town Archives. The method tries to be a graphic instrument of analysis to go in depth in the knowledge of the transition from the property and road land structure to the current urban form of the nineteenth century city expansion. In addition, the search have
\end{abstract}

1 Departamento de Ideación Gráfica Arquitectónica de la Universidad Politécnica de Madrid.

E-mail: luis.desobron@upm.es 
produced new information on the beginnings and dating of Colubi's plan, that is a top-rated cartographic document in the history of Madrid's urban development..

Keywords: cadastral plan; Carlos Colubi; urban form; city expansion; method; graphic reconstitution

\section{[fr] Le plan cadastral de Carlos Colubi: proposition méthodologique pour la reconstitution graphique du territoire madrilène au XIXe siècle}

Résumé. Il est proposé une méthode de reconstruction, sur une base cartographique actuelle, du Plan cadastral du territoire de Madrid élaboré par Carlos Colubi, en le considérant comme une image du territoire de Madrid au moment clé avant le processus de conception de l'Ensanche de la ville. Quatre phases de travail sont proposées, adaptant quelques approches déjà testées dans d'autres investigations, et en proposant de nouvelles basées sur les sources documentaires spécifiques du territoire et le moment historique étudié, principalement les plans de relevé et d'alignements des dossiers de construction du Archives de la Ville. La méthode essaye d'être un instrument graphique d'analyse, qui permet d'approfondir la connaissance de la transition de la structure de propiété et des routes rurales à la forme urbaine actuelle de l'Ensanche du XIXe siècle. En outre, les recherches effectuées ont permis d'obtenir de nouvelles données sur l'origine et la datation du plan de Colubi, document cartographique majeur de l'histoire de l'urbanisme madrilène.

Mots clés: plan cadastral; Carlos Colubi; forme urbain; ensanche; méthodologie; reconstitution graphique

Cómo citar. De Sobrón Martínez, L. (2019): El plano catastral de Carlos Colubi: propuesta metodológica para la reconstitución gráfica del terrazgo madrileño en el siglo XIX. Anales de Geografía de la Universidad Complutense, 39(2), 287-315.

Sumario. 1. Introducción. 2. Análisis del plano catastral de Carlos Colubi. 3. Metodología y fuentes documentales. 3.1. Primera fase: las persistencias o el parcelario rural bajo el parcelario urbano. 3.2. Segunda fase: los replanteos del ensanche, del plano al terreno. 3.3. Tercera fase: completar la tela de araña. 3.4. Cuarta fase: la lectura del relieve del territorio. 4. Conclusiones. 5. Referencias bibliográficas.

\section{Introducción}

La reconstitución gráfica de estados pasados de las ciudades, entendida como proceso de proyección de realidades desaparecidas, desde el presente hacia el pasado, sobre una misma base comparable, es un recurso ya aceptado como indispensable para cualquier investigación científica que pretenda profundizar en el conocimiento de la forma urbana de las ciudades y su evolución a lo largo de la historia ${ }^{2}$. De aquí el

\footnotetext{
2 "Sin abandonar el campo del pasado de la Arquitectura y ya centrándonos en los estudios de un determinado hecho, lugar o periodo, podríamos reconocer ejemplos en los que el Dibujo es la clave. La Reconstitución histórica, la búsqueda de la forma de un pasado desaparecido, es un caso evidente" (Martínez y Muñoz, 2016).
} 
interés en conocer y mejorar los métodos que se han planteado en los trabajos que, de un tiempo a esta parte, han proliferado en torno a la forma de la ciudad como objeto de estudio. En este sentido cabe destacar La forma de la Villa de Madrid (Ortega y Marín, 2004) como investigación pionera a la que han seguido otras, centradas en ámbitos más parciales, como el entorno del Palacio Real (Martínez, 2008), el barrio de Chamberí (Muñoz, 2008) o las antiguas puertas de la ciudad (Goitia, 2015), por mencionar sólo algunas de las que han tomado Madrid como objeto de estudio y la reconstitución gráfica, en el sentido arriba descrito, como método de investigación y conocimiento de sus estados pasados.

Este trabajo se centra en el estudio, como fuente principal, del plano catastral de Madrid que trazó Carlos Colubi, representación cartográfica del terrazgo madrileño en un momento clave para el desarrollo de la ciudad: la etapa de transición entre los procesos desamortizadores y la construcción del Ensanche. Los procesos urbanísticos y legislativos que se desarrollaron en estos años sentarían las bases de la evolución de la capital durante las siguientes décadas:

En efecto, en esa estructura territorial de las afueras de Madrid se incluye un parcelario rural específico y asimismo se integra una tipología peculiar de la propiedad rústica. Ahondar en las claves de la disposición y tamaño de las fincas ayuda a explicar el crecimiento futuro de la ciudad, al igual que recrear las estructuras de propiedad del ruedo urbano es indispensable para comprender su evolución temporal y funcionalidad. Es casi innecesario advertir el alto grado de dependencia que el crecimiento urbano decimonónico presenta con respecto a la estructura territorial (caminos, fincas, propietarios), de modo que una reflexión como la propuesta pudiera ser de interés para un buen grupo de ciudades españolas con estructuras territoriales similares.

(Mas, 1992).

Dicha estructura territorial de caminos, fincas y propietarios, de la que habla Mas, está reflejada en el plano catastral de Colubi, de forma análoga a como el trazado urbano, la configuración parcelaria y la misma sociedad madrileña del siglo XVIII están radiografiados en la Planimetría General de Madrid y la Visita General de 17501751 (Marín, 2000, 114).

El principal objetivo de este artículo es proponer un método para la reconstitución gráfica de la estructura territorial del entorno próximo a la Cerca de Felipe IV a mediados del siglo XIX, donde habría de proyectarse y construirse el Ensanche de Madrid. Sabemos que, consciente de la importancia del conocimiento y dominio de dicho territorio, Carlos María de Castro planteó realizar un levantamiento antes de estudiar el proyecto del Ensanche, para lo cual recabó una copia del plano de Colubi (Frechilla, 1989). Sobre la base cartográfica del plano catastral trazó Castro el de levantamiento, su primera propuesta de Ensanche, el anteproyecto finalmente aprobado en 1860 y numerosas modificaciones posteriores (Autor, año), todo lo cual determinó la forma urbana del crecimiento de la ciudad. Sabemos también que gran parte de dichas modificaciones tuvieron su origen en los intereses particulares y las 
presiones ejercidas por los principales propietarios de estos terrenos. Sabemos, finalmente, que el trazado de las principales vías estuvo condicionado por el curso de los principales caminos de salida de la ciudad y que la distribución de los solares en muchas de las manzanas del Ensanche madrileño responde a la lógica de las parcelaciones de las antiguas fincas rústicas. El análisis y la reconstitución gráfica del plano catastral de Carlos Colubi o, mejor, de la realidad que describe, cobra relevancia a partir de todas estas premisas. Se impone por ello una labor previa de documentación y análisis que permita avanzar en el escaso conocimiento que hasta ahora tenemos sobre las circunstancias de este importante documento, y que podemos considerar como un objetivo adicional.

Finalmente, se plantea la puesta en práctica y verificación del método propuesto aplicándolo a la reconstitución gráfica parcial de dicho territorio, en la zona comprendida entre la carretera de Aragón (hoy calle de Alcalá) al norte, la carretera de Valencia (hoy avenida Ciudad de Barcelona) al sur, el recinto del Real Sitio del Buen Retiro al oeste y el arroyo Abroñigal (hoy vía de circunvalación Calle 30), antiguo límite oriental del término municipal. Este ámbito geográfico corresponde con las secciones 17, 18, 19, 20 y 21 del plano de Colubi (Fig. 1).

\section{Análisis del plano catastral de Carlos Colubi}

El único ejemplar que conocemos del documento elaborado por Carlos Colubi titulado Plano catastral del Término de Madrid se custodia en el Archivo de Villa ${ }^{3} \mathrm{y}$ no se trata del original, sino de una copia fechada en 1889. De hecho, podría tratarse de una segunda copia realizada a partir de otra copia del plano original. Esto es lo que cabría inferir de la nota manuscrita al pie del último pliego del plano, que reza: "Es copia de la del plano parcelario del Sr. Colubi que existe en esta Oficina"4.

Lo que encontramos sobre su proceso de construcción en las referencias consultadas es escaso y confuso. Por un lado, hasta ahora se ha aceptado implícitamente la fecha de 1866 en que la Cartografía básica de la ciudad de Madrid (AAVV, 1979) data el plano del que se copió el que ahora conocemos. Efectivamente, la representación de determinados elementos urbanos en el plano apuntan a dicha fecha. El más llamativo de ellos quizá sea la línea del ferrocarril de contorno que comunicaba las estaciones del Norte y de Atocha y que se terminó de construir en 1866 (Álvarez et al., 1980). Sin embargo, Frechilla señala que ya en 1857 Carlos María de Castro solicitó una copia del plano de Colubi. Concretamente, en un informe de agosto indicaba Castro que "Bastaba solo para conseguir el objeto que me proponía en mis operaciones de campo rectificar en su día el espresado plano para

3 Archivo de Villa: 0’69-52-1. El plano se puede consultar en la biblioteca digital www.memoriademadrid.es.

${ }^{4}$ En la misma hoja está escrita otra nota sin firma, que parece redactada anteriormente, y reza: "Es copia del plano levantado de orden de la Junta de Evaluación por el Arquitecto Carlos Colubi”. 
conocer y apuntar en él las alteraciones ocurridas desde hace algunos años en que fue terminado"s.

Las indagaciones practicadas en el Archivo de Villa y en el Archivo Topográfico del Instituto Geográfico Nacional permiten afirmar que el plano catastral de Colubi se inscribe dentro del conjunto de iniciativas cartográficas desarrolladas a raíz de la reforma fiscal promovida en 1845 por el Ministro de Hacienda Alejandro Mon. Esta reforma instauraba un conjunto de impuestos entre los que se encontraba la Contribución territorial, que gravaba la renta de la tierra. El reglamento que la desarrolló obligaba a cada municipio a elaborar un trabajo de campo de medición y evaluación de las fincas (Arístegui et al., 2014) y a los propietarios a declarar las características de sus tierras ${ }^{6}$. El sistema de la Contribución territorial responsabilizaba a los ayuntamientos de asignar las cuotas a los propietarios, para lo cual era necesario tener un conocimiento detallado de su territorio, especialmente los grandes municipios, como el de Madrid. Por este motivo, el Real Decreto de 23 de mayo de 1845 establecía que en Madrid y en cualquiera de las principales capitales de provincia donde el Gobierno considerara conveniente se formara una Comisión especial, dependiente de la Dirección General de Contribuciones Directas, para llevar a cabo la evaluación y reparto de las cuotas a que estaban obligados los contribuyentes.

Como consecuencia de todo ello, entre 1848 y 1858 geómetras y agrimensores levantaron por encargo de numerosos ayuntamientos los conocidos como Planos Geométricos de Términos Jurisdiccionales. El Archivo Topográfico del IGN conserva una colección de dichos documentos, todos ellos de municipios de Cataluña y Baleares (Urteaga, 2017, 259). Constaban de un plano geométrico y un libro de registros. En el primero, se dividía el término en secciones y se asignaba un número a cada finca, representando linderos, caminos, cursos de agua y construcciones. En el segundo se registraba cada parcela y se dejaba constancia de la información considerada relevante para su evaluación: identificación de la parcela, nombres de los propietarios, clase de cultivo y superficie.

En Madrid, pese a los sucesivos retrasos provocados por la actitud obstruccionista de la Corporación municipal, en octubre de 1848 inició su andadura la Comisión de evaluación y reparto de la contribución territorial de Madrid ${ }^{7}$. Las reticencias del Consistorio se explican por cuanto la Comisión, que se encargaría de valorar la riqueza real del municipio, escapaba a su control, dado que el presidente estaba designado por la Dirección General de Contribuciones Directas del Ministerio de Hacienda. Y éste tenía, entre otras, la atribución de nombrar los empleados agentes

\footnotetext{
${ }^{5}$ AGA 31/08192. Informe de Carlos María de Castro de 13 de agosto de 1857.

${ }^{6}$ Real orden de 23 de diciembre de 1846. Gaceta de Madrid, $n^{\circ}$ 4484, 24 de diciembre de 1846.

${ }^{7}$ AV 4-82-59, "Espediente formado con motivo de haber remitido el Sr. Intendente a S. E. para su aprovación el presupuesto de 36.000 rs calculado para gastos de una nueva oficina de la Comisión de valúo y reparto de la Contribución de inmuebles de esta Capital que debe abonarse con fondos del común."
} 
investigadores y peritos para proceder a la tasación de las fincas rústicas, que serían previsiblemente profesionales independientes del Consistorio y libres, por tanto, de presiones políticas. Además, la Comisión estaba facultada para aprobar su propio presupuesto de gastos con cargo a las arcas municipales ${ }^{8}$.

Entre 1848 y 1849 la Comisión instó reiteradamente al Consistorio a aceptar el presupuesto de gastos propuesto ante "la necesidad de formalizar la estadística rústica de la Capital" ". Finalmente la Comisión acabó aprobando y trasladando al Alcalde Corregidor, en mayo de 1850, la cuenta de gastos de los trabajos de medición y evaluación dirigidos por Colubi "en la formación del Plano general del Término de esta Capital". En dicha cuenta se justificaban 2.500 reales para la compra de instrumentos; 39.360 reales para la parte facultativa, que incluía un arquitecto (Carlos Colubi), un delineante, un agrimensor y cinco peones, todos ellos por espacio de ocho meses de trabajo; 4.333 reales para los sueldos de un empleado y un escribiente; y 6.000 reales para gastos eventuales y extraordinarios ${ }^{10}$. Es también gracias a las cuentas de gastos de la Comisión que sabemos ahora que Colubi había empezado a trabajar para la misma en diciembre de 1849: “...en la cuenta de Diciembre de dicho año se justifican 2.400 reales satisfechos a los Arquitectos Dn. Carlos Colubi y Dn. José Antonio Pérez, por remuneración de los trabajos verificados en dicha Comisión" ". Podemos afirmar entonces que el equipo de trabajo dirigido por Carlos Colubi levantó y formó el Plano catastral del término de Madrid en los últimos meses de 1849 y los primeros de 1850. Estaba plenamente justificado que Castro plantease la necesidad de actualizar los contenidos del plano catastral en el levantamiento que dirigiera siete años después.

La copia que hoy conservamos del plano de Colubi es muy semejante en sus características a los Planos Geométricos de Términos Jurisdiccionales que conserva el Archivo Topográfico del IGN. Consta también de un plano parcelario y de un registro escrito de propietarios y propiedades. El contenido gráfico se compone de un plano de reunión a escala $1 / 7.500$ y 36 pliegos de papel vegetal de $65,5 \times 95 \mathrm{~cm}$. (AAVV, 1992) donde se trazan, con diferentes orientaciones y a escala $1 / 2.000$, cada una de las 36 secciones en que se distribuyen los terrenos extramuros de la ciudad hasta el límite del término municipal. Las reales posesiones de la Casa de Campo, la Florida y la Montaña de Príncipe Pío no quedan representadas en ninguna de las secciones por estar exentas de contribución. A su vez, Colubi agrupa las secciones en dos grandes ámbitos territoriales: el cuartel del norte (secciones 1 a 16,35 y 36 ) y el cuartel del sur (secciones 17 a 34). Los límites físicos entre ambos cuarteles son la calle y puente de Segovia, junto con la real posesión de la Casa de Campo, por un extremo de la ciudad, y la carretera de Aragón por el otro (Fig. 1).

\footnotetext{
${ }^{8}$ Real orden de 8 de diciembre de 1848 .

${ }^{9}$ AV 4-200-52 "Incidente relativo a que se faciliten a la junta de Evaluación de la riqueza Territorial los fondos necesarios para levantar la estadística de propiedad rústica."

${ }^{10}$ AV 4-200-52.

${ }^{11}$ AV 4-82-59.
} 
Figura 1. Esquema del recinto interior de Madrid y ámbito de estudio planteado para llevar a cabo la reconstitución gráfica propuesta ${ }^{12}$
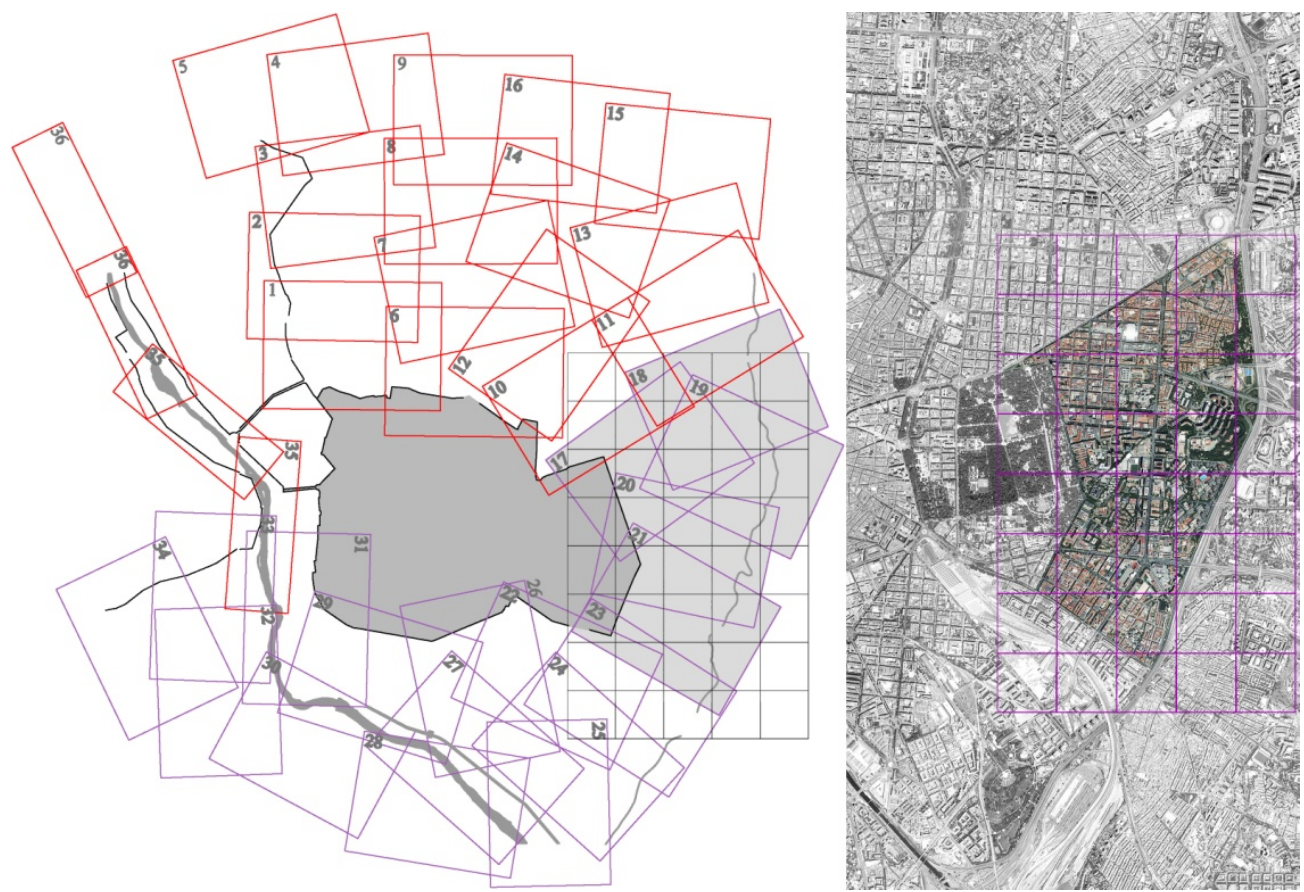

Fuente: Elaboración propia y Elaboración propia a partir de Ortofoto PNOA del Instituto Geográfico Nacional. Año 2015.

Como todo plano catastral, el de Colubi es un instrumento orientado al conocimiento de las propiedades inmobiliarias con fines contributivos, por lo que refleja aquella información que puede condicionar el valor de las parcelas: su ubicación, extensión, propiedades colindantes, comunicaciones, accesos,

\footnotetext{
${ }^{12}$ Izquierda: Esquema del recinto interior de Madrid en el que se indica el encuadre de los 36 pliegos, correspondientes a cada sección del Plano catastral del término de Madrid de Carlos Colubi. En rojo se han señalado los pliegos correspondientes a las secciones del cuartel del norte (1-16, 35 y 36) y en lila los correspondientes a las secciones del cuartel del sur (17-34). Se han sombreado los pliegos de las secciones 17 a 21, de las que se propone una reconstitución gráfica. Fuente: Elaboración propia.

Derecha: Ámbito de estudio planteado para llevar a cabo la reconstitución gráfica propuesta, correspondiente con las secciones 17 a 21 señaladas en la imagen izquierda. Cuadrícula de referencia de 500x500 metros. Fuente: Elaboración propia a partir de Ortofoto PNOA del Instituto Geográfico Nacional. Año 2015.
} 
infraestructuras próximas y bienes inmuebles que albergan (Fig. 2). No describe en cambio la altimetría del terreno, salvo indicación de la posición de taludes y terraplenes. En cada sección se definen a tinta negra linderos, cerramientos de parcelas y construcciones; vías, caminos y veredas con su arbolado; infraestructuras, como ferrocarril y puentes; accidentes geográficos, como cursos de agua y terraplenes; y rótulos. La tinta azul se utiliza para perfilar el contorno del río Manzanares y para el relleno de masas de agua en estanques y albercas. La tinta carmín se reserva generalmente para el relleno de masas construidas, para perfilar las tapias de cerramiento de los cementerios y para numerar las parcelas.

Figura 2. Pliego del Plano catastral del término de Madrid de Carlos Colubi correspondiente a la sección 17, cuartel del sur. Copia de 1889. Escala 1/2.000.

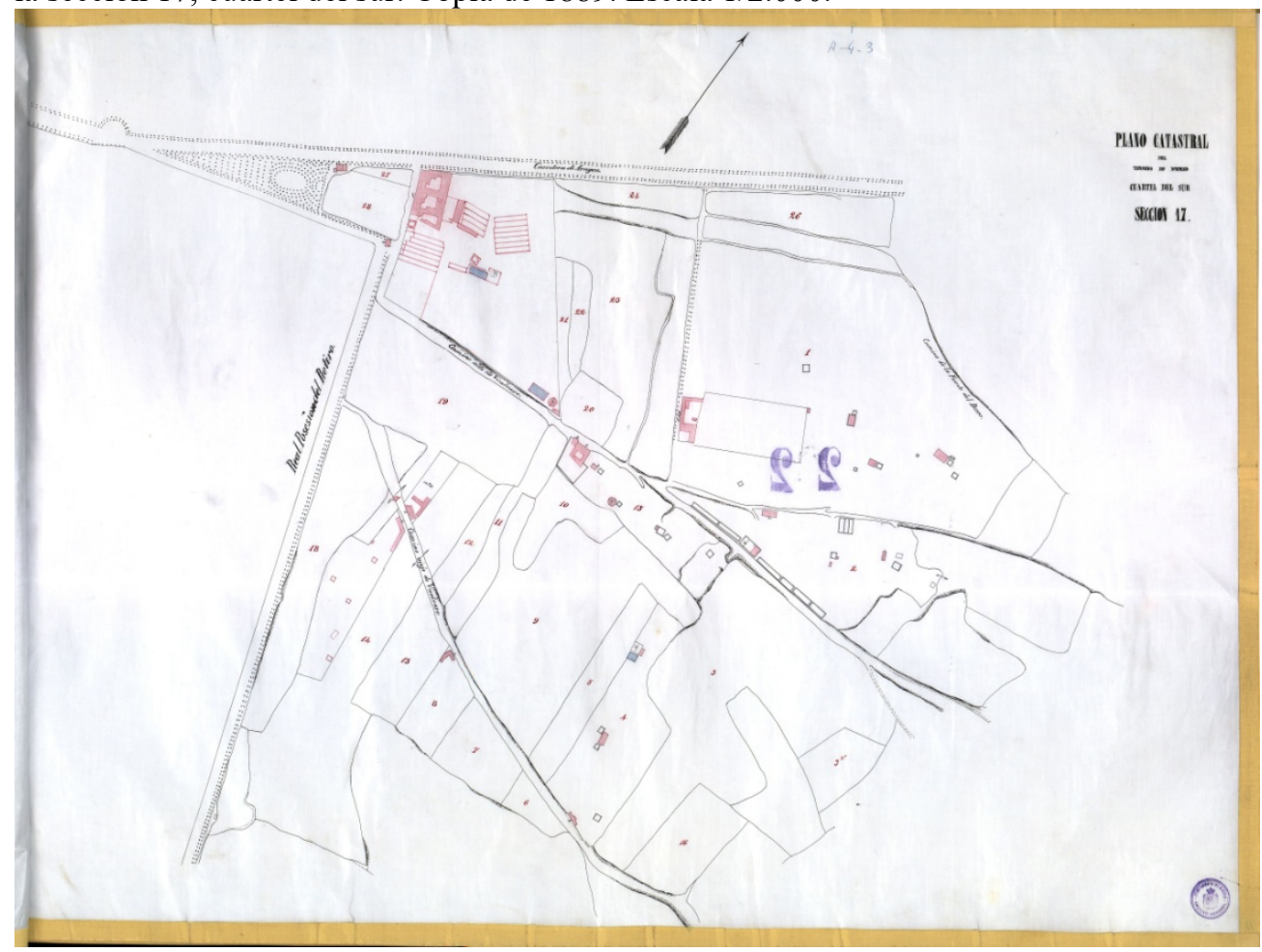

Fuente: Archivo de Villla, www.memoriademadrid.es

No obstante, los códigos de color empleados no son exactamente iguales en todos los pliegos del plano. Se aprecian algunas contradicciones que podrían estar indicando la participación de diferentes manos en el dibujo o cambios de criterio debidos a la elaboración del documento en diferentes etapas. 
Estas discrepancias de criterios gráficos y las diferencias en la caligrafía de la rotulación, indicios sutiles pero no desapercibidos tras un examen detenido, parecen distribuir los 36 pliegos del plano en dos conjuntos: 1-18 y 19-36. Estos dos conjuntos coinciden a grandes rasgos con los cuarteles norte y sur en que está repartido el conjunto del territorio representado ${ }^{13}$. De hecho, cuando en mayo de 1857 Castro propuso un plan de operaciones para llevar a cabo el levantamiento del territorio extramuros de la ciudad, planteó también la distribución del trabajo de campo en dos zonas, norte y sur, cuya delimitación, "la Cuesta de Areneros por un lado y el ángulo más avanzado del Retiro por el otro"14, coincide sensiblemente con los dos conjuntos referidos (1-18 y 19-36) en que hemos agrupado las secciones del plano de Colubi en función del grafismo empleado. No obstante, no se ha encontrado ningún indicio de que exista una relación directa entre estas dos circunstancias ${ }^{15}$.

En cuanto a la escala, también hay contradicciones entre las referencias que hace Castro del plano de Colubi y el documento que hoy día conocemos, a escala 1/2.000:

a) En comunicación del día 11 de julio de 1857, Castro indicaba que la escala del plano de Colubi era 1/2.500, asegurando que lo había podido comprobar personalmente: "Por una feliz casualidad he sabido posteriormente la existencia de un plano que en escala de 1/2.500 representa todo el término de Madrid egecutado concienzudamente y con esmerada perfección según he tenido lugar de examinar, por el Arquitecto Dn. Carlos Coluvi."16.

b) En el informe redactado por Castro el 13 de agosto de 1857 insistía en que estaba trazado a escala 1/2.500: "Contando ya entonces, con que el Gobierno de S. M. por su Ministerio de Hacienda poseía un plano comprensivo, en escala de 1/2.500 de todo el término de Madrid desde sus actuales tapias, y esperando obtener previsto permiso para tomar copia de él, escusado era gastar tiempo y dinero en repetir operaciones que el Arquitecto D. Carlos Colubi había llevado a cabo con minuciosidad esquisita." 17

Frechilla (1989) resuelve estas contradicciones suponiendo que el documento que examinó Castro fue una primera versión del plano catastral, hasta ahora no localizada. Esto explicaría que la copia que conservamos pudiera haber sido trazada a una escala

\footnotetext{
${ }^{13}$ Las secciones 17 y 18 , que pertenecen al cuartel sur, tienen sin embargo el grafismo de los pliegos del cuartel norte. Por el contrario, las secciones 35 y 36 se incluyen en el cuartel norte, pero comparten criterios gráficos con los pliegos del cuartel sur. Parece como si estas cuatro secciones pertenecieran, por sus características gráficas, a los cuarteles equivocados.

${ }_{15}^{14}$ AGA 31/08192.

${ }^{15}$ Es preciso señalar que en el informe posterior de 13 de agosto Castro describe detalladamente las dos zonas en que finalmente distribuyó el territorio para llevar a cabo el trabajo de campo, trasladando bastante más al sur el límite entre las dos zonas por el Este, hasta la carretera de las Cabrillas y la fuente de la Alcachofa.

${ }^{16}$ AGA 31/08192. Castro llega a sugerir que sea el propio Colubi quien saque la copia, abonándosele la cantidad que se acuerde, lo que nos indica que, siete años después de trazado el plano catastral, Colubi sigue trabajando para la Comisión de evaluación y reparto.

${ }^{17}$ AGA 31/08193.
} 
diferente del plano original, aunque aún desconocemos el motivo. En cualquier caso parece evidente que las copias sucesivas del plano forman parte de un proceso de actualización de la información que entra dentro de la lógica de un documento de control fiscal (Muñoz, 2008). Asimismo, la sucesión de copias, posiblemente parciales, podría explicar también las discrepancias y confusión señaladas anteriormente en los códigos gráficos empleados.

Por otro lado, el Registro de propietarios y propiedades que acompaña y complementa el plano, es un libro de asientos donde, después de una breve memoria descriptiva, se presentan dos listados por cada sección del plano. En el primer listado se enumeran las parcelas de la sección, indicando en cada una de ellas la clase de finca o uso a que se destina: tejar, tierra de secano, de regadío, jardines cercados, etc.; su clasificación en tierras de $1^{\mathrm{a}}, 2^{\mathrm{a}}$ y $3^{\mathrm{a}}$ calidad, realizada por el perito agrónomo José Nieto; el nombre del propietario; su cabida medida en fanegas, celemines y estadales $^{18}$; y observaciones, que suelen referirse a la existencia de construcciones. En el segundo listado se enumeran las construcciones con una descripción detallada en cuanto al uso, tipología y superficies por plantas. Podemos considerar este registro de propietarios un antecedente inmediato de las llamadas cédulas catastrales que planteó la Junta General de Estadística como complemento de la Planimetría catastral o Parcelario urbano de Madrid, para inventariar y valorar la riqueza urbana madrileña entre 1860 y 1876 (Camarero, 2011, 44).

El registro de propietarios que disponemos es, según anotación en la portada, copia sacada para uso de la Delegación Especial de Propietarios y Derechos de la Villa del Ayuntamiento con fecha de septiembre de 1884. Con toda seguridad se trata también de una actualización de un libro de registros anterior, pues tenemos constancia de la existencia de una serie de Libros de la propiedad territorial del Término de Madrid elaborados anualmente entre 1855 y 1876, excepto $1856^{19}$. Posiblemente la serie diera comienzo con el primer libro de registro de propietarios y propiedades elaborado por el equipo de Colubi, el cual debió de redactarse durante los años posteriores a la formación del plano ${ }^{20}$.

\footnotetext{
${ }^{18}$ La obligatoriedad de implantar el Sistema Métrico Decimal en todos los documentos oficiales se dispuso el 21 de marzo de 1855 por una Real Orden del Ministerio de Fomento (Puente 1982), por lo que el libro de registro de propiedades y propietarios elaborado por el equipo de Colubi estaba sujeto a una Real Orden anterior de la Dirección General de Contribuciones, concretamente a la de 2 de julio de 1853, según la pequeña memoria descriptiva redactada al principio del mismo libro.

${ }^{19}$ Archivo de Villa. Inventario de Secretaría LXXXIV.

${ }^{20}$ En septiembre de 1853 la Comisión de evaluación y reparto publicaba la Evaluación de todos los edificios públicos exentos de contribución que existen en Madrid y su término, con espresión de su cabida, valor en capital y renta, según valoración practicada por el Arquitecto de dicha Comisión, D. Carlos Colubi (AV 5-200-3).
} 


\section{Metodología y fuentes documentales}

El método El método propuesto de reconstitución gráfica del territorio extramuros de Madrid en el momento anterior inmediato al inicio del proceso proyectual del ensanche de la ciudad, refiriéndolo a la base cartográfica del plano catastral actual ${ }^{21}$, se desarrolla en cuatro fases. Cada una de las tres primeras fases supone el trazado de un conjunto de elementos identificables en el plano catastral de Colubi:

1) Elementos invariantes o persistencias.

2) Elementos desaparecidos o transformados, cuya posición y tamaño se encuentran acotados en fuentes documentales gráficas, generalmente planos de un ámbito muy reducido, como una o varias parcelas urbanas.

3) Elementos desaparecidos cuya posición sólo conocemos gracias a documentación cartográfica a escala pero no acotada, es decir, planos urbanos de un ámbito suficientemente amplio como para que no sea posible acotar o medir con suficiente precisión elementos a escala de parcela urbana.

4) La cuarta fase plantea el uso de recursos gráficos para visualizar el relieve del terreno, que es una información ausente en el plano de Colubi.

El proceso es acumulativo, por lo que cada una de las fases condiciona y es el punto de partida y apoyo de la siguiente. Al mismo tiempo, cada fase implica, respecto de la anterior, un mayor grado de interpretación de la documentación disponible y, por tanto, un menor grado de certeza en cuanto a la posición y el tamaño de los elementos representados.

Como se ha indicado al principio, existen numerosos antecedentes relativamente recientes que recurren a la reconstitución gráfica como instrumento de investigación. Implícita o explícitamente plantean procesos o métodos de trabajo que suelen compartir algunas premisas y planteamientos. Esta propuesta intenta adaptarlos a las circunstancias específicas de los territorios donde habría de desarrollarse el ensanche decimonónico y a las características de las fuentes documentales disponibles en este caso. Detengámonos en su estudio.

\subsection{Primera fase: Las persistencias o el parcelario rural bajo el parcelario urbano}

La primera fase de trabajo se fundamenta en la premisa de que aquellos elementos que no han experimentado cambios en el tiempo, coinciden en el espacio (Ortega y Marín, 2004). Consiste en llevar a cabo un análisis comparativo entre la cartografía histórica y la actual para identificar aquellos elementos que persisten en el tiempo. Estos elementos, cuya posición y tamaño podemos considerar ciertos, serán las

\footnotetext{
${ }^{21}$ Para la puesta en práctica del método propuesto se ha empleado la cartografía vectorial catastral de Madrid, obtenida en la página web de la Sede Electrónica del Catastro, y la cartografía vectorial municipal, ambas referidas al sistema ETRS89 en proyección UTM.
} 
referencias fundamentales en ulteriores fases del proceso de reconstitución. Naturalmente, la cantidad de estas referencias que podemos encontrar se reduce conforme nos desplazamos hacia atrás en la línea del tiempo por las transformaciones que experimentan, en su devenir, el espacio urbano y el espacio rural.

Figura 3. Detalle del proceso de identificación de linderos en una zona de la sección $\mathrm{n}^{\circ} 17$ del Plano catastral del término de Madrid (derecha) en el plano parcelario actual del Ayuntamiento de Madrid (izquierda) ${ }^{22}$.

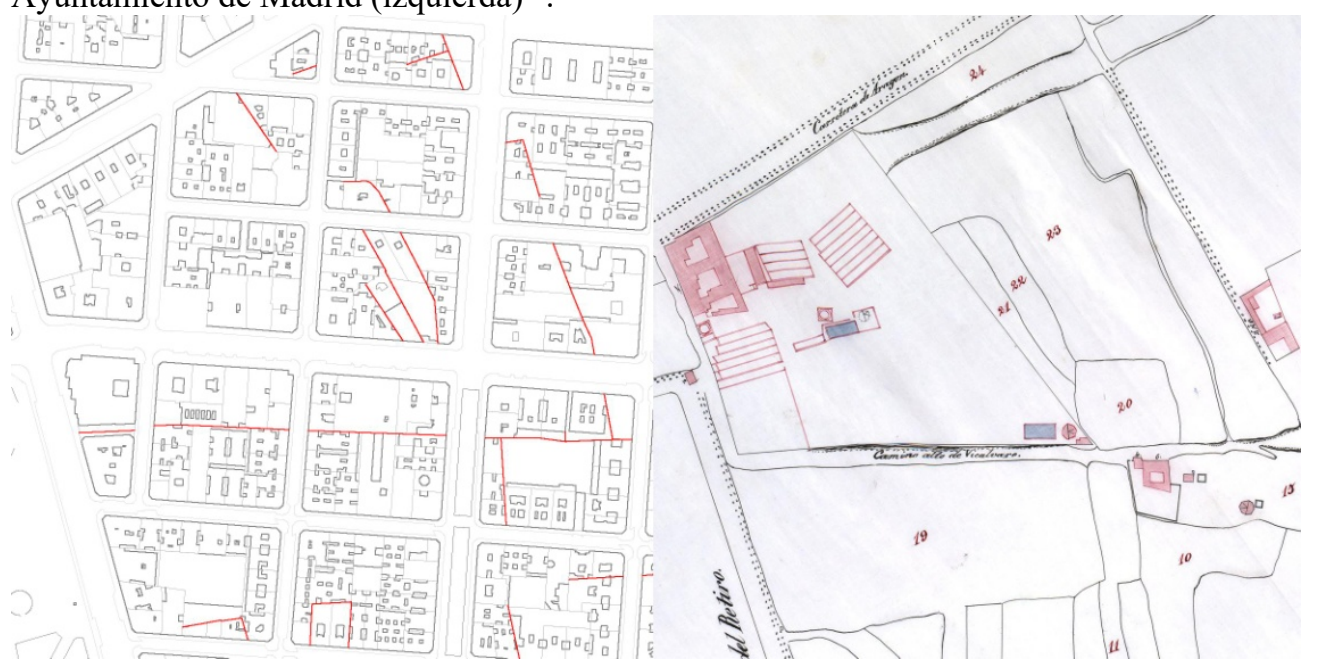

Fuente: Elaboración propia.

Todos los antecedentes consultados coinciden en este planteamiento inicial de identificación de invariantes, si bien aquellos que toman como ámbito de análisis zonas urbanas históricamente consolidadas, buscan edificios que se conserven actualmente sin alteraciones de su planta, o bien sus solares (Martínez, 2008; Temes, 2008; Sancho et al., 2017). En el caso que nos ocupa, la fuente documental principal es el plano catastral de Carlos Colubi. Al tratarse de una zona eminentemente rural en el momento previo a la construcción del Ensanche, el análisis de las persistencias se reduce casi siempre a la búsqueda e identificación de linderos de propiedades inalterados.

\footnotetext{
${ }^{22}$ Obsérvese cómo los linderos del fondo de los solares pares de la calle de O’Donnell (centro de la imagen izquierda), señalan el trazado del eje del antiguo Camino Alto de Vicálvaro (centro de la imagen derecha).
} 
Figura 4: Identificación de las persistencias del plano catastral de Colubi (en color rojo) sobre el plano parcelario actual del Ayuntamiento de Madrid en la zona al Este del Retiro. Cuadrícula de referencia de 500x500 metros.

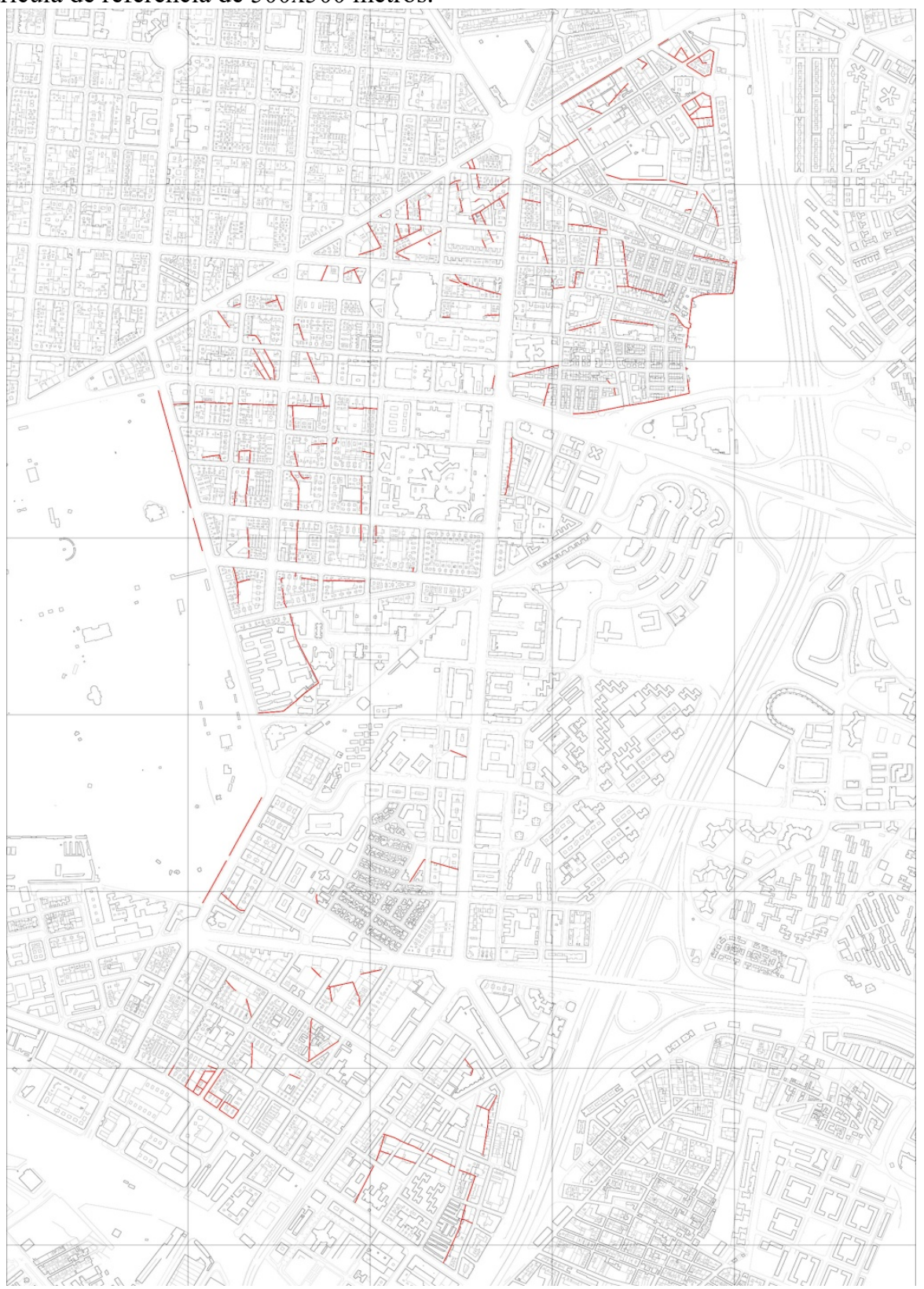

Fuente: Elaboración propia. 
A pesar de las numerosas modificaciones operadas, los límites de la propiedad rural persisten parcialmente en el tejido urbano actual, ya que los rudimentarios mecanismos legales de urbanización decimonónicos no alteraban la configuración de las propiedades en tanto no afectara a la superficie que debía ser ocupada por los espacios públicos planificados. La irregularidad del parcelario rural madrileño del siglo XIX permite identificar, dentro de las manzanas de la ciudad actual, la configuración más o menos singular de numerosos linderos del plano de Colubi (Fig.3). Se genera así una red de persistencias o invariantes cuya densidad redunda en una mayor precisión del resultado obtenido en la reconstitución gráfica (Fig. 4).

\subsection{Segunda fase: Los replanteos del Ensanche, del plano al terreno}

Una vez aprobado el anteproyecto del Ensanche de Madrid, en julio de 1860, los técnicos de la Oficina del Ensanche, dirigidos por Castro, procedieron a replantear sobre el terreno los ejes de las vías proyectadas. Este proceso, que acarreó numerosas modificaciones sobre la marcha de la posición y dimensiones de las vías proyectadas (Autor, año), se materializaba en la construcción de unos cotos de fábrica de ladrillo que indicaban sobre el terreno la posición de las intersecciones de los ejes de las futuras calles.

El proceso de urbanización del Ensanche iba por detrás de la actividad constructiva de los propietarios de suelo, de modo que era la iniciativa de edificar la que ponía en marcha el mecanismo administrativo para garantizar las alineaciones proyectadas. La tramitación de la licencia municipal para construir en una parcela daba comienzo con la solicitud de la tira de cuerdas a instancia del propietario. Este procedimiento consistía en el replanteo de la alineación de fachada a partir de los ejes de las calles definidos por la posición de los cotos sobre el terreno. El resultado final era la expropiación de suelo privado para destinarlo a vías públicas. Pero cuando se daba el caso de caminos y veredas propiedades del común, destinadas a desaparecer por atravesar áreas propuestas para ser edificadas, el Ayuntamiento obligaba a comprar a los propietarios colindantes. En no pocos casos la configuración de parcelas, caminos y vías proyectadas daban lugar a procesos de expropiación y apropiación simultáneos, que se resolvían parcialmente por compensación de unas superficies con otras. Las relaciones que de ello se derivaron entre la administración y los propietarios, concretadas en forma de trasvases de suelo de manos particulares a públicas en unas ocasiones, y en sentido inverso en otras, han generado multitud de expedientes que se conservan en el Archivo de Villa. Formando parte de ellos existe una nada despreciable cantidad de croquis y dibujos que dan cuenta de las operaciones de replanteo preceptivas para comprobar las alineaciones.

El conjunto de estos documentos constituye la fuente documental primordial en esta segunda fase del trabajo y su interés para el asunto que nos ocupa radica en la información que contienen acerca de las áreas destinadas a ser expropiadas o apropiadas, las cuales se triangulaban y acotaban y, lo que es más importante, las 
cotas están referidas a las alineaciones finales de la edificación en su estado actual (Fig. 5). En numerosas ocasiones el cálculo numérico de las superficies se realizaba sobre el mismo plano. Estos croquis nos permiten ubicar con precisión los puntos de intersección entre los antiguos linderos y caminos y las actuales alineaciones o medianeras de los edificios.

Figura 5: Plano de alineaciones de los terrenos de D. Pedro Villanueva y Sn. Román donde se acota la superficie destinada a ser expropiada para abrir las calles de Hermosilla y Fuente del Berro. Escala 1:500. 17 de marzo de 1880.

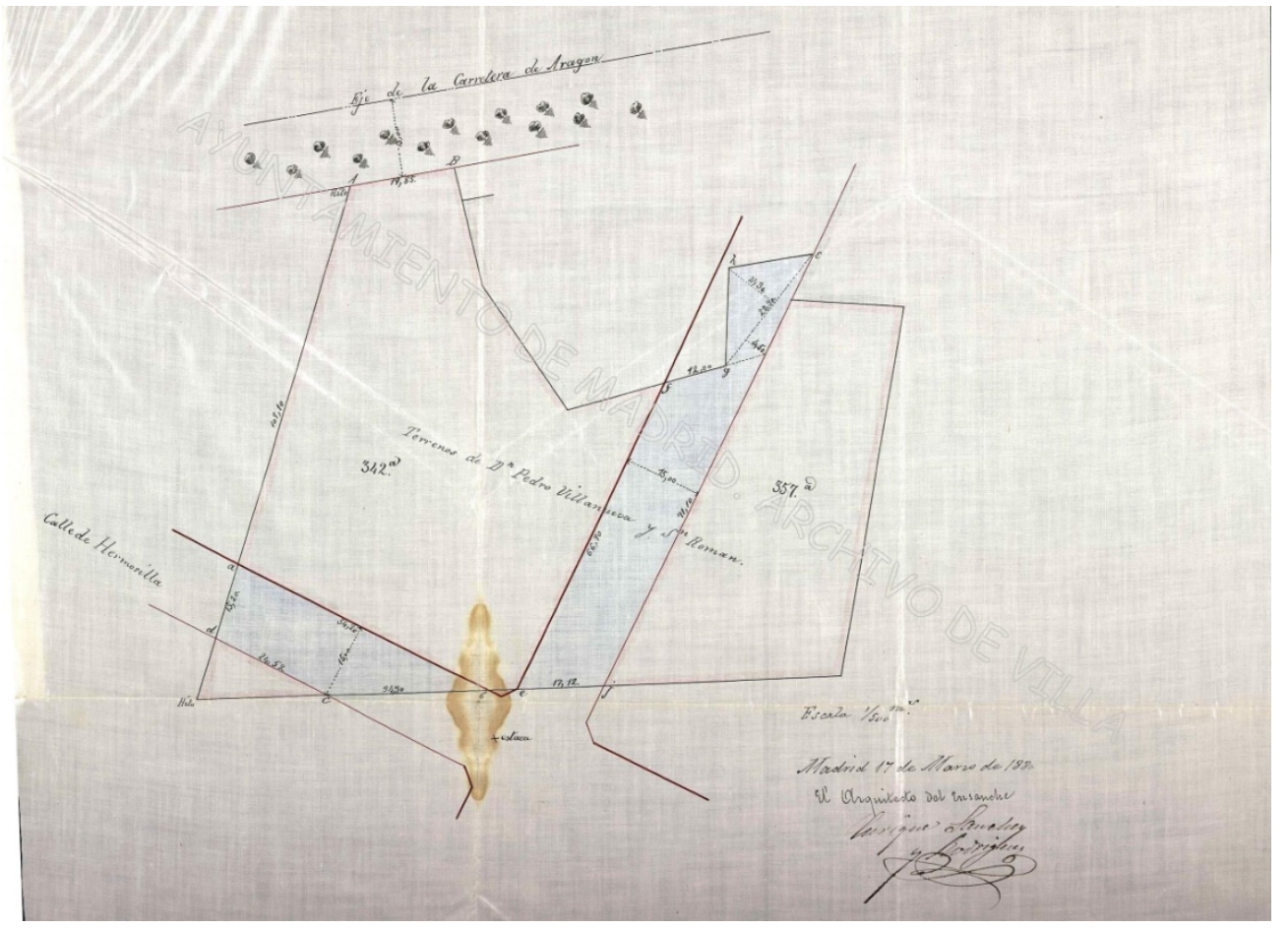

Fuente: Archivo de Villa, 45-104-27.

Estos documentos gráficos que, considerados individualmente, no parecen tener especial interés en el estudio de la forma urbana y su evolución histórica, considerados en su conjunto conforman un mosaico de planos acotados de los terrenos ocupados por la retícula del Ensanche madrileño y permiten construir una segunda red, que extiende la primera conformada a partir de las persistencias, reduciendo el grado de incertidumbre de la siguiente fase del método (Fig. 6). 
Figura 6: Reconstitución gráfica de linderos y caminos rurales del plano catastral de Colubi (en color morado) sobre el plano parcelario actual a partir de la información acotada de los planos de alineaciones y tira de cuerdas de los expedientes de construcción consultados. Cuadrícula de referencia de 500x500 metros.

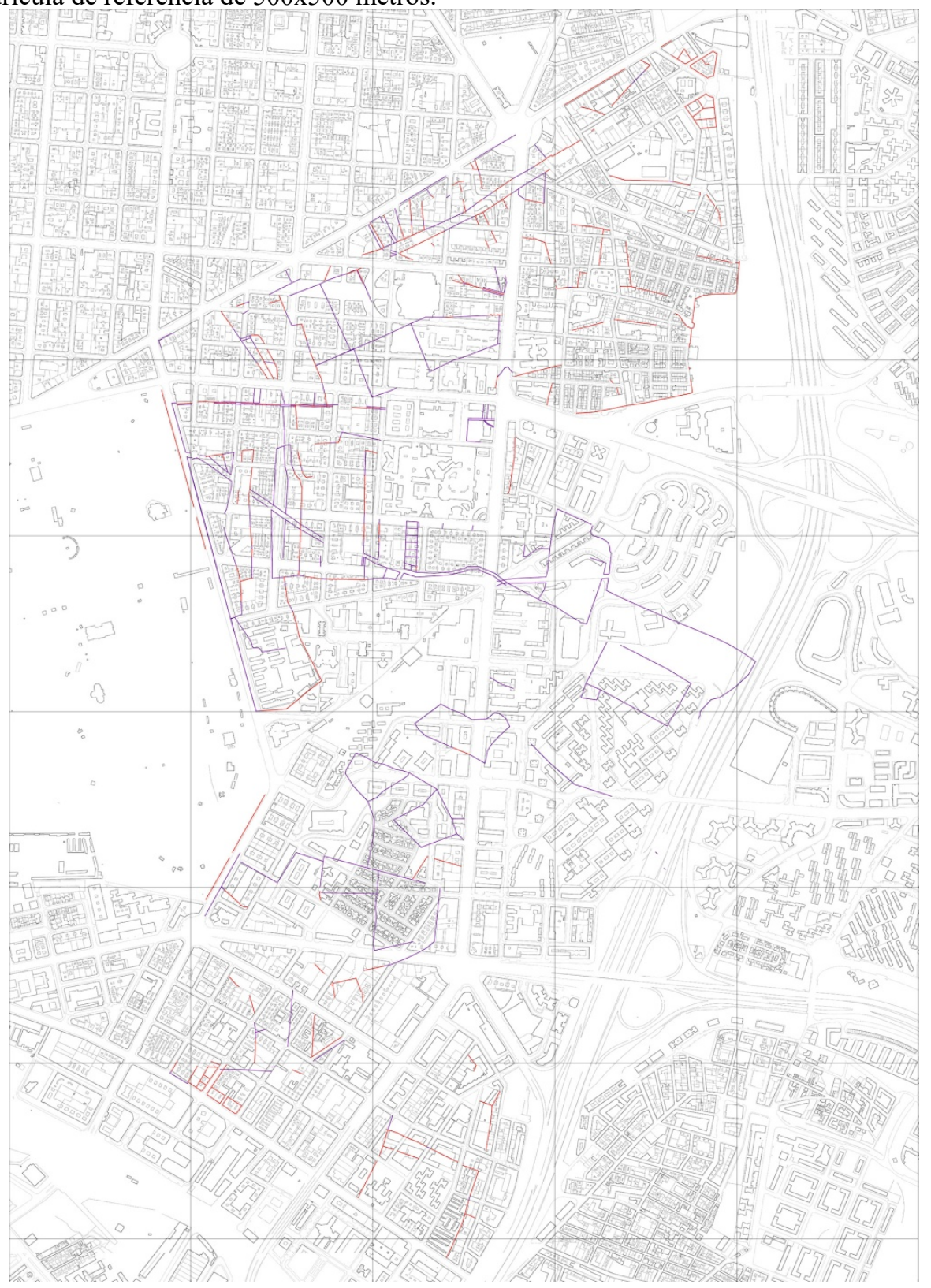

Fuente: Elaboración propia. 
Entre los numerosos expedientes de expropiación consultados para la reconstitución gráfica del plano de Colubi al Este del Retiro, cabe destacar el correspondiente a la apertura de la nueva avenida de la Plaza de Toros, hoy avenida de Felipe II, que requería la expropiación de cerca de $15.000 \mathrm{~m} 2$ de terreno de cinco propietarios diferentes. Los seis planos de replanteo y alineaciones elaborados por Alejo Gómez ${ }^{23}$, uno general y cinco de cada una de las fincas expropiadas, han permitido ubicar con precisión antiguos linderos de algunas propiedades singulares de la zona. Entre ellas la finca La Montellana, posesión que fue de D. Vicente Beltrán de Lis, y la conocida como Tierra larga del Camino Viejo ${ }^{24}$, propiedad de Doña Bernardina Muñoz. Esta última, cuyo perímetro ha sido posible identificar casi por completo en las dos primeras fases del método, coincide con el primitivo trazado del camino de Alcalá en su salida de Madrid antes de su rectificación, llevada a cabo probablemente dentro del plan de mejoras de los accesos a la ciudad y de los paseos exteriores a la Cerca promovido durante el reinado de Fernando $\mathrm{VI}^{25}$ (Fig. 7). Dicho antiguo trazado aún se puede identificar en algunos planos históricos como los que dibujaron Luis de Surville y Francisco Nangle para ilustrar unas maniobras militares realizadas en 1767.

El caso del antiguo camino de Alcalá, que en 1791 era todavía tierra de Propios de la Villa ${ }^{26}$, ilustra el proceso por el que unos terrenos propiedad del común, al perder su función como vía de comunicación, acaban siendo enajenados a manos privadas. Caminos como el de la Fuente del Berro, el Alto de Vicálvaro, el Viejo de Vicálvaro, el Bajo de Vicálvaro, o el de Valderribas, entre otros, hubieron de ser forzosamente comprados por los propietarios colindantes para poder edificar en sus parcelas. A cada propietario cuyo solar tenía frente a un camino enajenable le correspondía el semiancho de dicho camino en la longitud de todo su frente. Algunas de las actuales medianeras señalan el trazado del eje de los antiguos caminos rurales, de modo que el curso del antiguo Camino Alto de Vicálvaro se puede identificar a lo largo de los fondos de parcela de los números pares de la actual calle de O’Donnell (Fig. 3).

\footnotetext{
${ }^{23}$ AVM 5-290-1.

${ }^{24}$ AVM 16-422-5 y 8-158-7.

${ }^{25}$ Goitia (2015) documenta un plan de ensanche y urbanización del camino de Alcalá concebido por Ardemans en 1691, pero es poco probable que la rectificación del camino se produjera en fecha tan temprana.

26 "En Madrid a seis de Diziembre de mil setezientos nobenta y uno: En la Junta de Propios y Sisas celebrada este día se hizo entre otros el acuerdo del tenor siguiente: Hízose presente el expediente causado a instanzia de Antonio Martínez Vezino de esta Corte, solicitando, se le conceda arrendamiento de la tierra, que ocupa al Camino viejo, que antiguamente se llevava para Alcalá inmediato a la Venta del Spiritu-Santo..." (AV 3-84-14).
} 
Figura 7. Detalle de la reconstitución gráfica $^{27}$
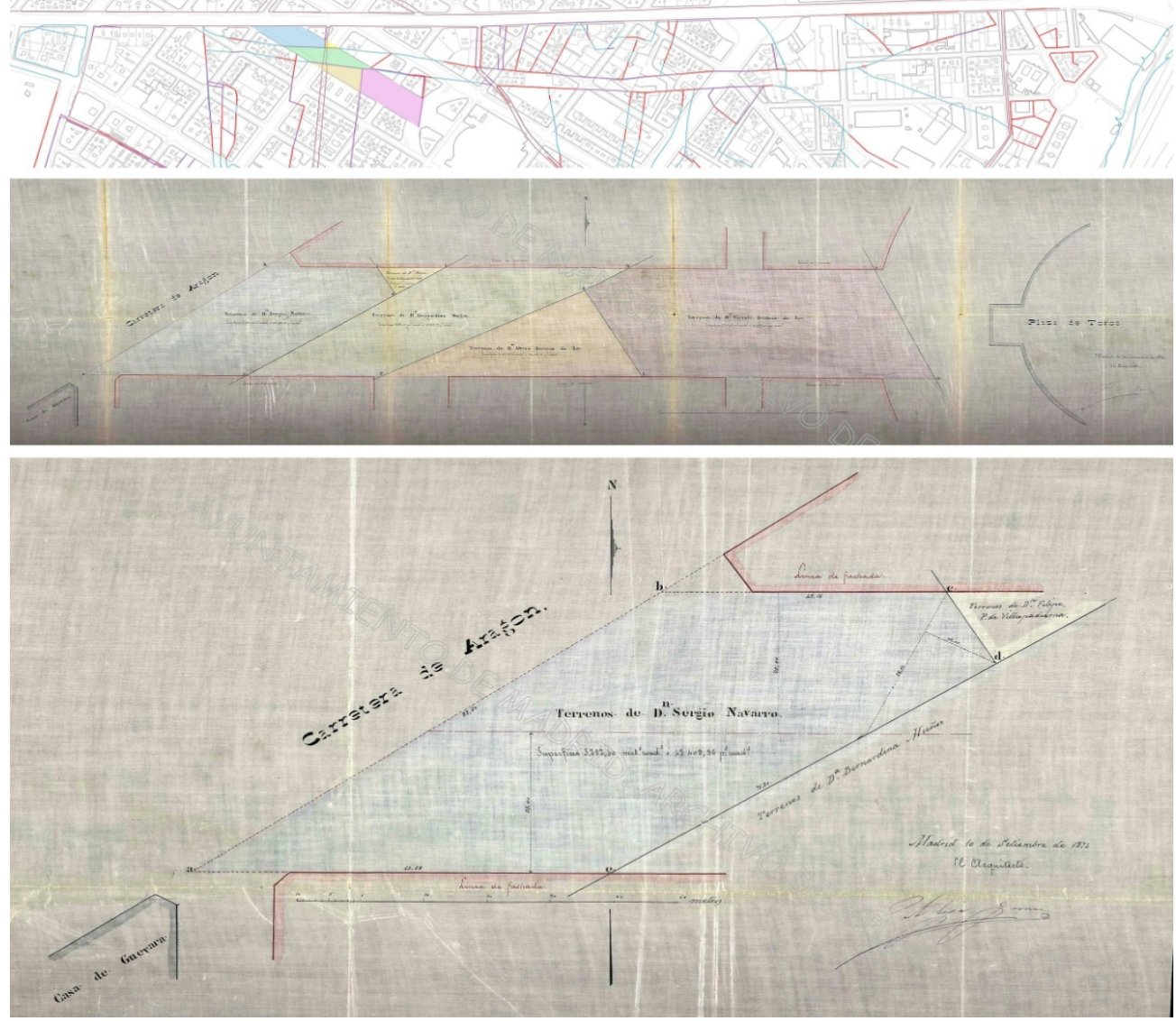

Fuente: Archivo de Villa, 5-290-1.

${ }^{27}$ Arriba: detalle de la reconstitución gráfica donde se aprecia el curso en curva del antiguo camino de Alcalá al sur del trazado rectificado que hoy es la calle de Alcalá. Se han señalado en línea de color los elementos correspondientes a las tres fases iniciales de la reconstitución: rojo (1), morado (2) y cyan (3). Se ha señalado con sombreados en color las fincas expropiadas para la apertura de la nueva avenida de la Plaza de Toros. Fuente: Elaboración propia.

Medio: plano general de alineaciones para la expropiación terrenos y apertura de la nueva avenida de la Plaza de Toros (hoy avenida de Felipe II). Arquitecto: Alejo Gómez. 10 de septiembre de 1874. Fuente: Archivo de Villa, 5-290-1.

Abajo: plano de detalle con alineaciones de los terrenos de D. Sergio Navarro. 
Figura 8: Plano de la tira de cuerdas practicada en la manzana $n^{\circ} 299$ del plano oficial del Ensanche con la situación del Camino Viejo de Vicálvaro, (en el arranque de la actual calle de Menorca, indicando las expropiaciones correspondientes, 8 de enero de 1920.

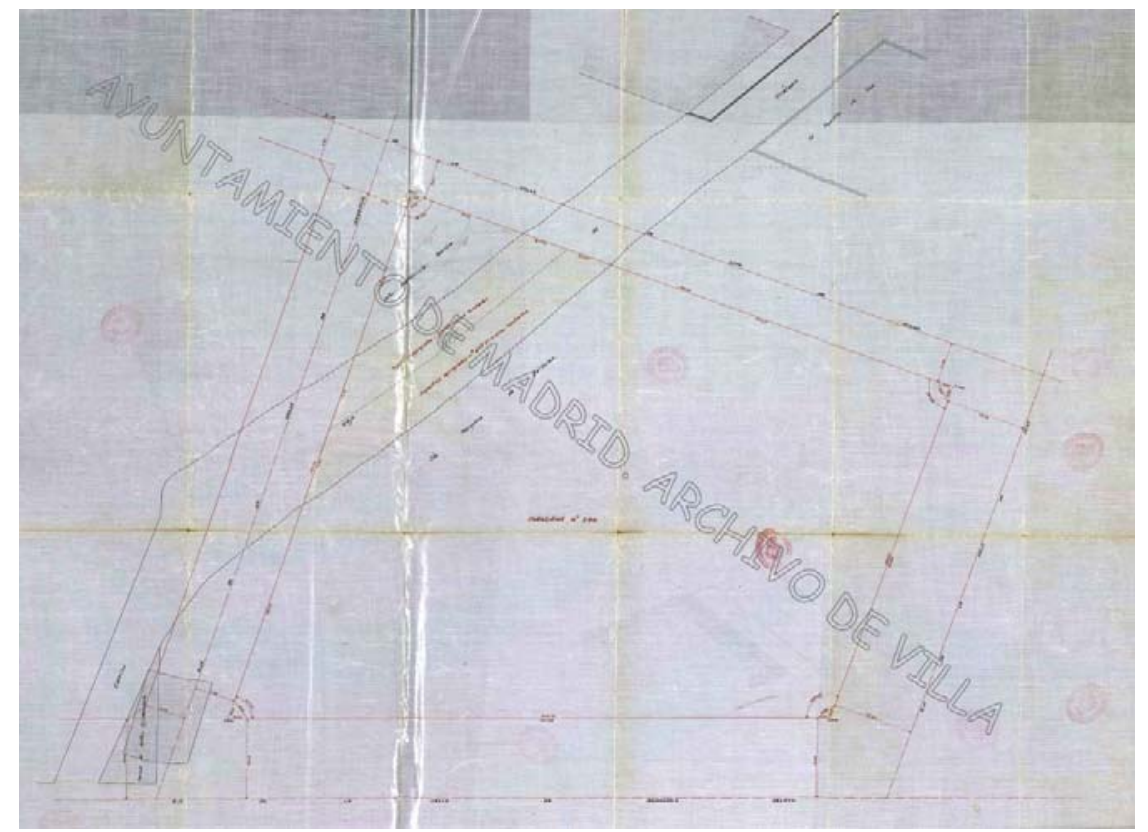

Fuente: Archivo de Villa, 8-158-12.

Otros, como el Camino Viejo de Vicálvaro, han podido ser localizados con precisión a partir de los planos de alineaciones, deslindes y tira de cuerdas de todos los solares que atravesaba en su recorrido (Fig. 8).

\subsection{Tercera fase: Completar la tela de araña}

La tercera fase del método propuesto consiste en la reconstitución gráfica de aquellos elementos desaparecidos o transformados de los cuales no disponemos de información más precisa que la de la cartografía histórica dibujada a escala pero sin acotar numéricamente. En nuestro caso la fuente primordial de esta fase vuelve a ser el plano catastral de Colubi.

Como es sabido, no es posible encontrar una coincidencia exacta de ángulos y distancias entre la cartografía histórica y la cartografía actual. Esto es así por diversos motivos: por el diferente grado de precisión alcanzado en los procesos de medición y levantamiento, dependiente de la tecnología disponible en cada momento; por los diferentes sistemas de proyección empleados, sobretodo en cartografía que hace uso de grandes escalas; y por las deformaciones que sufren los soportes donde se trazaron 
y el necesario manejo de reproducciones digitales de los dibujos originales (Ortega, 1996; Sancho et al., 2017).

Sabiendo que, si en la primera fase del método podíamos contar con la certidumbre de la presencia de los vestigios y en la segunda con la que puede proporcionarnos la veracidad de las medidas tomadas sobre el terreno, en esta tercera fase debemos conformarnos con lograr una aproximación coherente y justificada.

Para llevar a cabo esta aproximación Sancho, Agustín y Llopis (2017) proponen la georreferenciación y, si se considera necesario, georrectificación de la cartografía histórica mediante el empleo de Sistemas de Información Geográfica. El término georreferenciación se define como el proceso de asignar a ciertos puntos, identificados como invariantes en un documento cartográfico, unas coordenadas referidas al sistema de proyección elegido, sin deformar la imagen ráster del documento. A partir del cálculo de los valores residuales de cada punto de referencia y del valor residual medio se puede valorar la precisión del documento y proceder, si se estima conveniente, a la georrectificación. Esto es, la transformación geométrica de la imagen ráster con un algoritmo adecuado. Este procedimiento, que no deja de ser una interpretación de la cartografía histórica mediante algoritmos matemáticos, podremos considerarlo preciso en la medida en que la red de puntos de referencia obtenida en las dos primeras fases de trabajo sea suficientemente densa y que la elección de la transformación geométrica se lleve a cabo con buen criterio, en función del análisis de los datos y documentos disponibles.

En el caso que nos ocupa. Se han georreferenciado los cinco pliegos correspondientes a las secciones 17, 18, 19, 20 y 21 del plano de Colubi, aplicando en un principio sólo transformaciones de escalado y rotación de las imágenes ráster del plano, para comprobar su grado de fiabilidad geométrica. Los errores medios calculados por el software empleado ${ }^{28}$ varían entre los 3,97 metros en el pliego de la sección 17 y los 7,04 metros en el pliego de la sección 20. Es preciso tener en cuenta que las secciones 17,18 y 21 describen ámbitos que fueron en su mayor parte urbanizados antes de la Guerra Civil, mientras que las secciones 19 y 20 lo fueron, también en su mayor parte, después del conflicto armado. La consecuencia es que los procedimientos de urbanización de las zonas correspondientes a las secciones 17, 18 y 21 dieron lugar a una trama urbana en manzana cerrada, donde, como se ha podido comprobar, es relativamente sencillo encontrar persistencias. Por el contrario, el tardío desarrollo en edificación abierta de las zonas correspondientes a las secciones 19 y 20 se llevó a cabo con sistemas de planeamiento y de gestión del suelo donde desaparece el rastro de los linderos de la parcelación rural en el proceso de urbanización. Aquí, los puntos de referencia empleados han tenido que ser deducidos a partir de planos particulares de levantamiento o de deslindes de parcelas.

\footnotetext{
${ }^{28}$ Se ha empleado el software de código abierto QGIS 2.14, que se distribuye bajo la Licencia Pública General GNU.
} 
Figura 9: Composición a partir de las imágenes ráster correspondientes a las secciones 17, 18, 19,20 y 21 del plano catastral de Colubi, georreferenciadas y georrectificadas sobre la base del plano catastral actual.

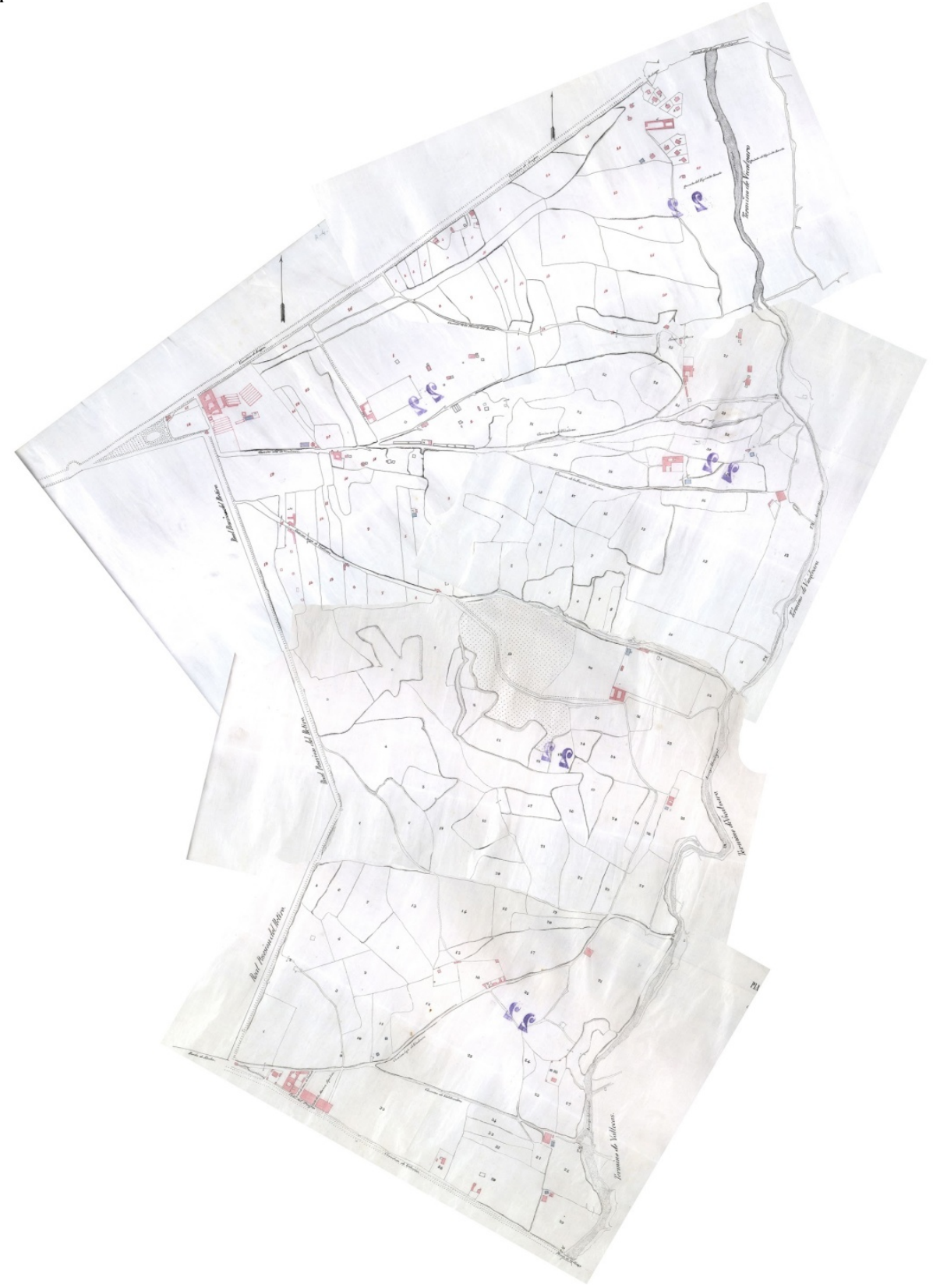

Fuente: Elaboración propia. 
Figura 10: Las dos primeras fases del método se completan con una tercera: la reconstitución gráfica sobre la base cartográfica del plano parcelario actual de elementos desaparecidos a partir de la georreferenciación y georrectificación del plano catastral de Colubi. Cuadrícula de referencia de 500x500 metros.

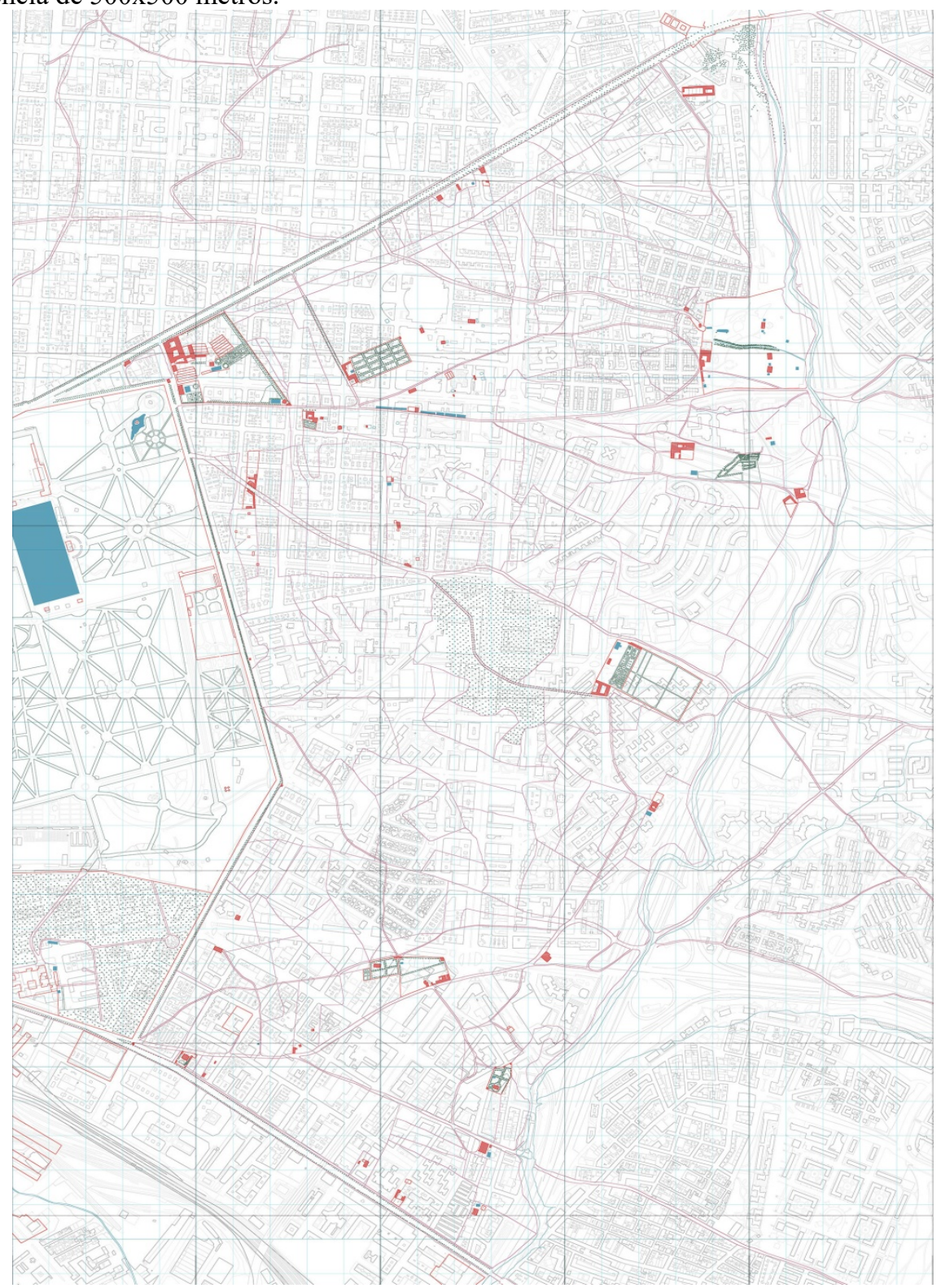

Fuente: Elaboración propia. 
Una vez realizadas estas comprobaciones se ha procedido a georrectificar las imágenes raster mediante una transformación polinómica de primer grado, lo cual introduce una distorsión mínima en las imágenes ráster que permite, por otro lado, un mejor cosido de los contornos de las secciones entre sí (Fig. 9). Aceptando las limitaciones de esta aproximación, se ha completado la reconstitución del plano de Colubi con el trazado de aquellos elementos cuya posición aún no había sido definida en las dos primeras fases (Fig. 10).

\subsection{Cuarta fase: La lectura del relieve del territorio}

Se propone como último paso el mapeo o proyección de la reconstitución gráfica trazada en el plano sobre un modelo 3D del terreno para, mediante operaciones de renderizado con sombras, obtener una lectura en planta de la forma tridimensional del territorio. El objetivo de esta última fase no es dotar a la reconstitución gráfica de unas coordenadas altimétricas precisas sino facilitar la visualización y comprensión de la relación entre los elementos representados (parcelaciones, construcciones y vías de comunicación) y la orografía del terreno, especialmente en aquellas zonas en las que ésta cobra cierto protagonismo. Dado que el plano catastral de Colubi no define la altimetría del soporte físico, ha sido preciso recurrir a levantamientos topográficos posteriores.

El primer plano con representación de la altimetría de Madrid mediante curvas de nivel, medidas en pies castellanos, fue el Plano de conducción de aguas a Madrid, trazado en 1848 por los ingenieros Juan Rafo y Juan Ribera. Este plano está dibujado a escala 1/12.500 pero el encuadre se ajusta al perímetro de la Cerca fiscal, por lo que apenas define la altimetría del ámbito del plano de Colubi.

El siguiente plano de Madrid con curvas de nivel del terreno es el de levantamiento trazado en 1857 bajo la dirección de Carlos María de Castro a escala 1/2.500 (Autor, año). Para Castro el conocimiento del soporte físico donde había de proyectar el Ensanche era un requisito de primordial importancia. Las curvas de nivel cada metro definen en este plano la altimetría del ámbito estudiado, aunque en algunas zonas se aprecian con dificultad por el deterioro físico del documento (Autor, año) (Fig. 11).

Posteriormente, entre 1861 y 1876, la Junta General de Estadística llevó a cabo otros levantamientos con el fin de elaborar el Parcelario urbano de la Villa de Madrid, entre cuyos documentos se cuentan las llamadas Hojas Kilométricas, trazadas a escala 1/2.000 con curvas de nivel también cada metro. A pesar de que se trazaron tres series de Hojas Kilométricas del término municipal, no se conserva 
ninguna completa en el ámbito de estudio considerado ${ }^{29}$, por lo que la información de la que disponemos es parcial.

Figura 11: Restitución de las curvas de nivel del plano de levantamiento trazado en 1857 bajo la dirección de Carlos María de Castro, en la zona de Madrid al Este del Retiro. Cuadrícula de referencia de 500x500 metros.

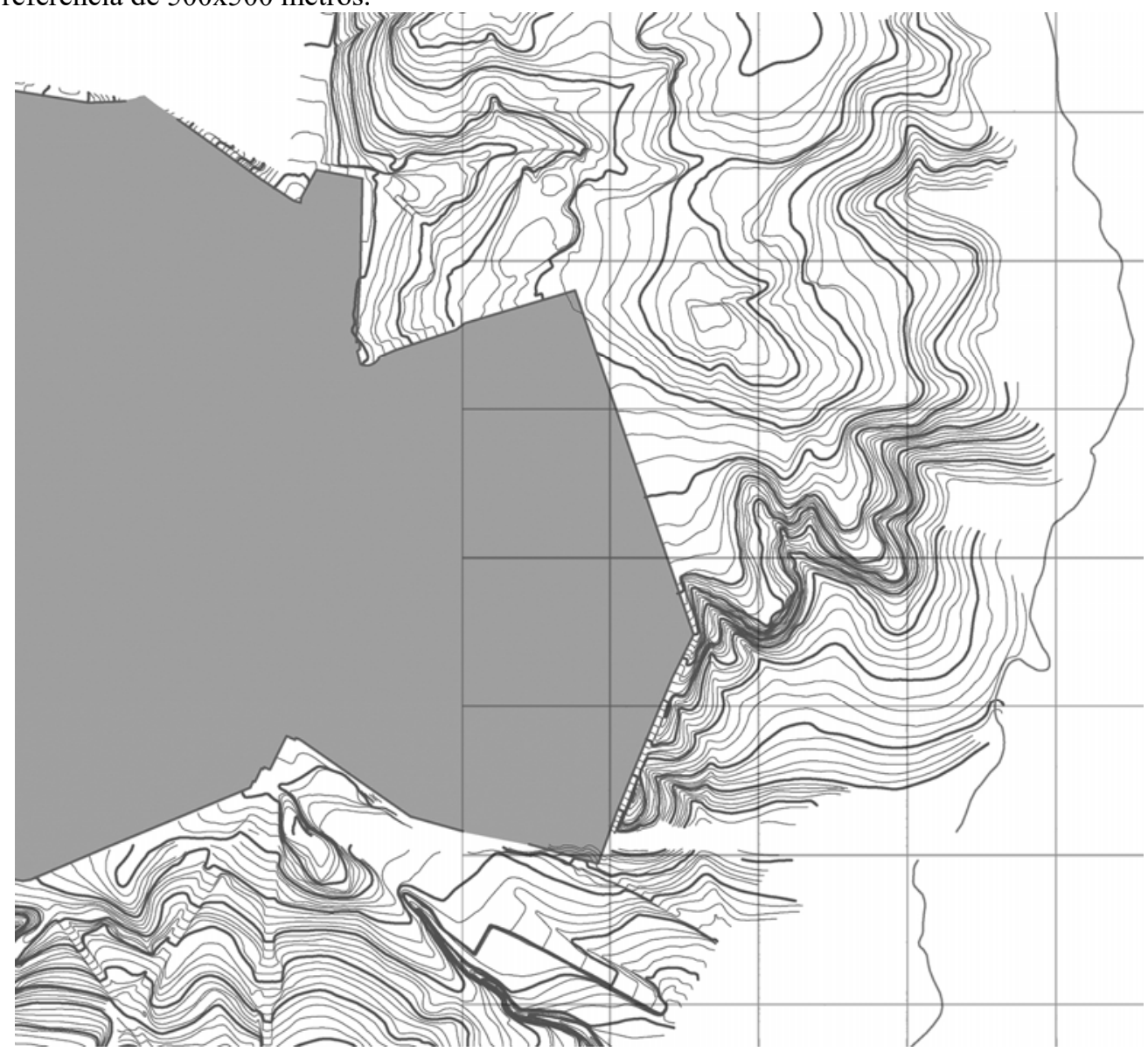

Fuente: Elaboración propia.

${ }^{29}$ Se conservan planos pertenecientes a tres series diferentes: de una se conservan las hojas 10D, 11D, $11 \mathrm{E}, 9 \mathrm{~F}, 11 \mathrm{~F}, 9 \mathrm{G}$ y $10 \mathrm{G}$; de otra las hojas 9E y 10F; y de la tercera las hojas 10D, 11D y 10H. Algunas hojas están duplicadas en diferentes series pero de otras no se conserva ejemplar en ninguna de ellas. 
Figura 12: Reconstitución gráfica de la zona de Madrid al Este del Retiro proyectada sobre el modelo 3D del terreno para permitir la lectura y comprensión del soporte físico. Cuadrícula de referencia de 500x500 metros.

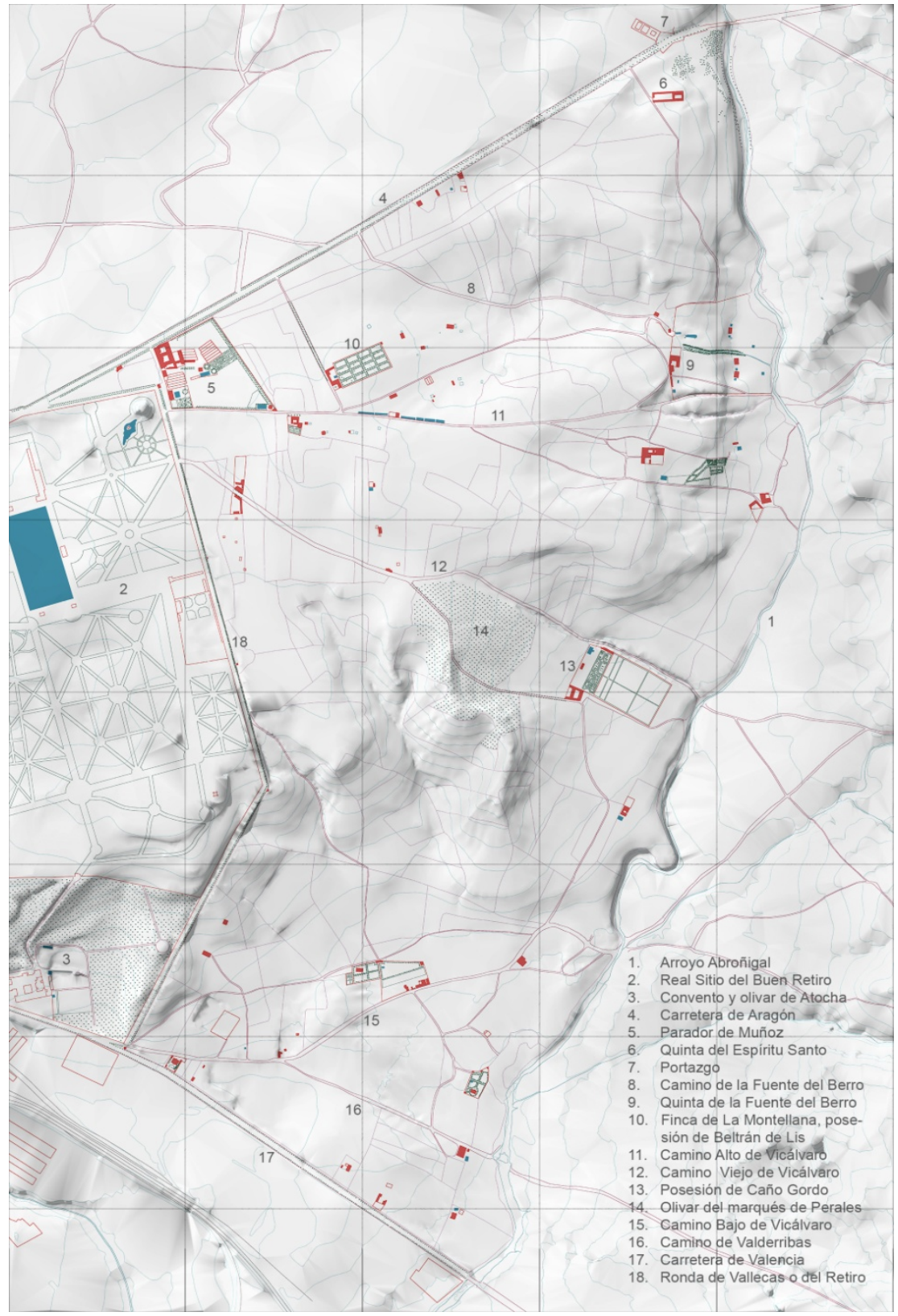

Fuente: Elaboración propia. 
Sabemos que en los años transcurridos entre el levantamiento de Castro y la elaboración de las Hojas Kilométricas apenas varió la fisionomía de la zona de estudio. Sin embargo, se aprecian inconsistencias entre ambas altimetrías. Cabría atribuir estas diferencias de precisión a los breves plazos con que contaron los equipos de trabajo dirigidos por Castro para efectuar las mediciones sobre el terreno ${ }^{30}$.

Las fuentes documentales empleadas en esta fase han sido el plano de levantamiento de Castro y las Hojas Kilométricas. En aquellas zonas donde se han encontrado discrepancias entre ambas cartografías se ha adoptado una solución de compromiso. El resultado obtenido guarda un reconocible parecido a las representaciones mediante sombreados del relieve del territorio que encontramos en documentos anteriores, como el plano de Nangle, el de Surville o los planos derivados de los trazados por los ingenieros militares franceses durante y después de la Guerra de la Independencia (Fig. 12).

\section{Conclusiones}

La reconstitución gráfica, sobre un sistema de referencia común, del territorio extramuros de Madrid en el momento previo al proceso proyectual del Ensanche se justifica por cuanto mejora el entendimiento de la relación entre el crecimiento de la ciudad decimonónica y la estructura viaria y parcelaria rural previa, por tanto profundiza en el conocimiento del proceso de transición del espacio rural al espacio urbano durante las siguientes ocho décadas de construcción de la ciudad.

El método propuesto para la reconstitución gráfica del terrazgo madrileño de mediados del siglo XIX parte de planteamientos y métodos ya explorados por otros/as autores/as, e intenta adaptarlos a las peculiaridades históricas y urbanas de los terrenos estudiados $\mathrm{y}$ a las fuentes cartográficas y documentales específicas disponibles: fundamentalmente el Plano catastral del término de Madrid trazado bajo la dirección de Carlos Colubi, y los planos de tira de cuerdas y alineaciones trazados para los procesos de expropiación de futuras vías y apropiación de antiguos caminos, conservados en los expedientes de construcción del Ensanche del Archivo de Villa.

La importancia del plano de Colubi es doble ya que se trata del primer plano catastral de las fincas rústicas del término municipal y, además, sirvió de base cartográfica para el plano de levantamiento sobre el que Carlos María de Castro trazó el anteproyecto del Ensanche de la ciudad. El análisis y las indagaciones realizadas sobre la copia que conservamos del plano de Colubi han permitido profundizar en el conocimiento sobre el origen y la formación del documento original desaparecido. Gracias a estas averiguaciones ahora podemos datar su trazado inicial entre 1849 y

\footnotetext{
${ }^{30}$ Los trabajos de campo para la medición de toda la zona norte, entre la posesión de La Florida y la carretera de las Cabrillas, fueron ejecutados por dos brigadas entre julio y noviembre de 1875 .
} 
1850, por encargo de la Comisión especial para la evaluación y reparto de la contribución territorial de Madrid, dentro de las actuaciones relacionadas con la reforma fiscal de Alejandro Mon, que dieron también lugar a los Planos Geométricos de Términos Jurisdiccionales, con los que el plano de Colubi mantiene no pocas similitudes.

La identificación, sobre la cartografía actual, de persistencias o elementos que no han variado de posición, es el punto de partida de todos los trabajos que hacen uso de la reconstitución gráfica de estados históricos de la ciudad como instrumento de investigación. Estos vestigios suelen ser límites de propiedades, linderos o bordes de caminos, que sobreviven camuflados en la trama urbana actual, y evidencian la estructura territorial originaria que subyace en la ciudad actual, por tanto, la pervivencia del plano de Colubi en el plano catastral actual.

A partir de estas persistencias, consideradas como elementos fundamentales de referencia, la recuperación del trazado de elementos ya desaparecidos o transformados es un proceso más interpretativo. Otras investigaciones han recurrido para este segundo paso al uso de software de Sistemas de Información Geográfica con el que georreferenciar y, en su caso, georrectificar la cartografía histórica.

Una aportación original del método propuesto en este trabajo es la realización de un paso intermedio a los dos anteriores, consistente en la localización precisa de elementos desaparecidos o transformados a partir de la información contenida en una fuente documental gráfica que habitualmente no es considerada, frente a la cartografía histórica general: los planos acotados de replanteo y alineaciones para expropiaciones y apropiaciones referidos anteriormente. Este paso intermedio permite extender la red inicial de elementos de los que conocemos con certeza su posición, reduciendo al mínimo los datos sometidos a interpretación y mejorando la precisión del último paso de la reconstitución gráfica, al contar con un mayor número de puntos de referencia.

Este planteamiento, cuya eficacia se ha podido comprobar en zonas con tejido urbano característico de los ensanches decimonónicos, sin embargo, se ve limitado en aquellos ámbitos urbanos que, por circunstancias históricas, se han desarrollado más recientemente, bajo premisas de planeamiento y gestión urbana diferentes, y donde los linderos de la parcelación rural desaparecen casi por completo en los procesos de urbanización.

Otra aportación original es la de proponer, mediante técnicas de mapeo y renderizado, una lectura gráfica de la relación entre la estructura de la propiedad, las vías de comunicación y el relieve del terreno. Dado que la información altimétrica es inexistente en el plano catastral de Colubi, ha sido preciso buscarla en levantamientos topográficos de años posteriores. En este caso hablamos del plano de levantamiento trazado en 1857 bajo la dirección de Carlos María de Castro y de las Hojas Kilométricas elaboradas desde la Junta General de Estadística.

El método propuesto se ha llevado a la práctica con la reconstitución gráfica de la zona de Madrid al Este del Retiro, comprendida en las secciones $n^{\circ} 17,18,19,20$ y 21 del plano catastral de Colubi. El resultado gráfico alcanzado (Fig. 12) supone en sí mismo una contribución al conocimiento y comprensión de una parte del entorno próximo de Madrid en el momento crítico previo a su expansión. 
Aunque este estudio se centra en el caso madrileño, dada la homogeneidad del marco legislativo de los ensanches en España y su permanencia a lo largo de los procesos de proyecto y construcción, cabría estudiar su aplicación a la reconstitución gráfica del entorno urbano del conjunto de ciudades españolas que experimentaron procesos de ensanche en la segunda mitad del siglo XIX y primer tercio del XX, con las reservas derivadas de la documentación gráfica y cartográfica específica disponible en cada caso.

\section{Referencias bibliográficas}

AA.VV. (1979): Cartografía básica de la ciudad de Madrid. Planos históricos, topográficos y parcelarios de los siglos XVII, XVIII, XIX y XX. Madrid, Colegio Oficial de Arquitectos de Madrid.

AA.VV. (1992): Los planos de Madrid y su época. Madrid, Ayuntamiento de Madrid.

Álvarez, A., Palomar, P. y Sánchez, J.M. (1980): Desarrollo histórico de la zona sur de Madrid. En Álvarez, A. (coord.): Las estaciones ferroviarias de Madrid. Su arquitectura e incidencia en el desarrollo de la ciudad. Madrid, Colegio Oficial de Arquitectos de Madrid, $147-205$.

Arístegui, A. et al. (2014): Catálogo de documentos del Archivo Topográfico del IGN (III). Boletín Informativo de la Sociedad Española de Cartografía, Fotogrametría y Teledetección, 13, 4-17.

Camarero, C. (2011): Planimetría catastral de Madrid, Villa y Corte, de los siglos XVIII y XIX. En: Montaner, C. et al. (editores), Cartografia i agrimensura a Catalunya i Balears al segle XIX. Barcelona, Institut Cartogràfic de Catalunya, 29-46.

Frechilla, J. (1989): La construcción del Ensanche de Madrid. Tesis doctoral inédita. Madrid, ETSAM-UPM.

Goitia, A. (2015): Transformaciones urbanas en torno a las reales puertas de la Villa de Madrid (1656-1860). Tesis doctoral inédita. Madrid, ETSAM-UPM.

Marín, F. J. (2000): Planimetría general de Madrid y visita general de casas, 1750-1751. Catastro, 39, 87-114.

Martínez, A. (2008): Espacio, tiempo y proyecto. El entorno urbano del Palacio Real de Madrid entre 1735 y 1885 . Madrid, Ayuntamiento de Madrid.

Martínez, A. y Muñoz, M. J. (2016): El Dibujo: método y conclusión en la Investigación en Arquitectura. En Actas del 16 Congreso Internacional de Expresión Gráfica Arquitectónica. Alcalá de Henares, Universidad de Alcalá, 1061-1068.

Mas, R. (1992): Mayorazgos, quintas y longueros en los alrededores del antiguo Madrid. Historia urbana. Revista de historia de las ideas y de las transformaciones urbanas, 1, 5570.

Muñoz, M.J. (2008): Chamberí, s. XIX. Trazas en la ciudad. Tesis doctoral inédita. Madrid, ETSAM-UPM.

Ortega, J. y Marín, F. J. (2004): La forma de la Villa de Madrid. Soporte gráfico para la información histórica de la ciudad. Madrid, Comunidad de Madrid. 
Ortega, J. (1996): Entre retículas y triángulos: Una revisión gráfica de los planos madrileños. En: La representación de la ciudad. II Historia de la representación urbana: hitos, códigos y tradiciones. Actas del VI Congreso Internacional de Expresión Gráfica Arquitectónica. Pamplona, T6 Ediciones, 215-224.

Puente, G. (1982): El Sistema Métrico Decimal. Su importancia e implantación en España. Cuadernos de Historia Moderna y Contemporánea, 3, 95-125.

Sancho, M., Agustín, L. y Llopis, J. (2017): Análisis y generación de cartografías historiográficas en el estudio de la evolución de la forma urbana: el caso de la ciudad de Teruel. EGA Expresión Gráfica Arquitectónica, 30, 180-189. https://doi.org/10.4995/ega.2017.7845

Temes, R. (2008): Las fuentes catastrales y la identificación de las transformaciones en los tejidos urbanos. CT Catastro, 64, 55-78.

Urteaga, L. (2017): El espacio urbano en la cartografía catastral, siglos XVIII y XIX. En: Urteaga, L. y Nadal, F. (editores): Historia de la cartografía urbana en España. Madrid, Centro Nacional de Información Geográfica, 255-286. 